\title{
REVIEW
}

\section{The use of bronchial challenge to diagnose asthma in preschool children}

\author{
*Simon Godfrey ${ }^{a}$ \\ ${ }^{a}$ Emeritus Professor of Paediatrics, Hadassah-Hebrew University, Hadassah University Hospital, Jerusalem 91120, Israel
}

Received 23rd September 2008; revised 8th December 2008; accepted 17th December 2008; online 27th January 2009

\begin{abstract}
Wheezing and respiratory symptoms are very common in preschool children, and the ability to diagnose asthma correctly is important. This review describes an approach to the diagnosis of asthma in preschool children by means of an inhalation bronchial challenge. The child is exposed to increasing doses of challenge agent until wheezing is detected at a dose below that at which normal subjects respond, thus indicating bronchial hyperreactivity. The technique was originally developed using simple stethoscope auscultation of the lungs together with recording of respiratory rate and oxygen saturation (by pulse oximetry). Extensive studies have confirmed the safety and practicability of the technique and the specificity for asthma when the challenge agent is adenosine 5'-monophosphate (AMP). Subsequently, acoustic recordings have been used to detect and analyse breath sounds and to quantify the wheeze; these show excellent correlation between the clinical detection of wheeze and the wheeze rate (duration of wheeze/duration of recording) during bronchial challenges in children. Equipment is now becoming available that can perform the acoustic quantification of wheeze automatically and facilitate bronchial challenges in young children.

(C) 2009 General Practice Airways Group. All rights reserved.

S Godfrey. Prim Care Resp J 2009; 18(1): 10-14.

doi:10.3132/pcrj.2009.00008
\end{abstract}

Keywords asthma, wheeze, diagnosis, paediatrics, preschool, bronchial challenge

\section{Contents}

Background

10

Introducing the 'PCwheeze'

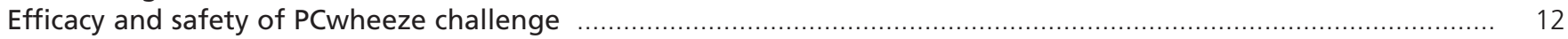

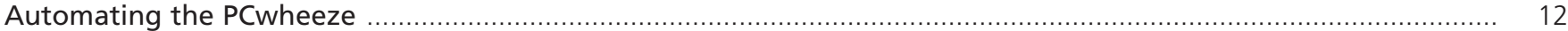

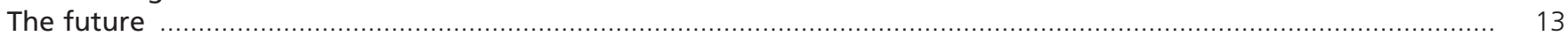

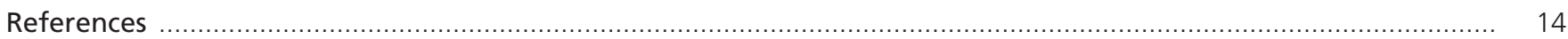

\section{Background}

Two years ago in this Journal, Bush gave an excellent review of the problems of diagnosing asthma in children under five years of age. ${ }^{1}$ In his introductory remarks he noted that all children cough at some time, up to about half of them will also wheeze before they reach school age, but that nevertheless most children are healthy. He stated that the general practitioner (GP), faced with a child with chronic and relatively non-specific symptoms such as cough, wheeze, and breathlessness, has to decide into which category of illness to place the child:
- The child is normal but may have minor non-specific complaints of a transient nature.

- The child has a serious but uncommon disease such as cystic fibrosis, an inhaled foreign body or a congenital anomaly of the airway.

- The child has asthma.

Bush reviewed the clinical pointers and other tools available to help make the correct diagnosis, ${ }^{1}$ and he pointed out that failure to categorise the young child with respiratory symptoms correctly may result in unnecessary suffering particularly when appropriate treatment could bring relief or

\footnotetext{
* Corresponding author: Professor Simon Godfrey, Hadassah-Hebrew University, Hadassah University Hospital, Ein Kerem, Jerusalem 91120 , Israel. Tel: +972 25635277 Fax: +972 25631601 E-mail: sgodfrey@netvision.net.il
} 
Figure 1. Bronchial challenge with methacholine showing the fall in $\mathrm{FEV}_{1}$ as percent of predicted normal plotted against the dose of methacholine being inhaled. The endpoint is determined as the dose of methacholine causing a $20 \%$ fall in $\mathrm{FEV}_{1}$ which is termed the $\mathrm{PC}_{20}$.

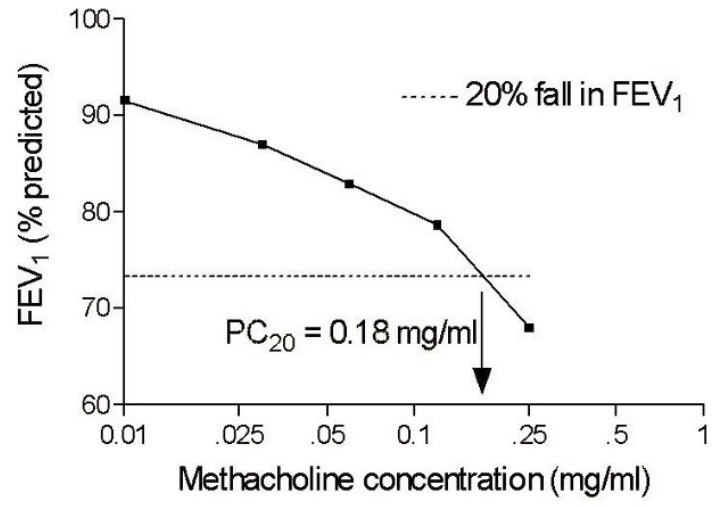

prevent permanent damage. In older children lung function testing serves as a hallmark of asthma diagnosis, but this is impractical in the preschool age group - although there are some complicated techniques (that are not widely applicable) which can be used in infants s.3 $^{2,}$ or co-operative preschool children. ${ }^{4-6}$

It is normally possible to distinguish clinically between the normal child and one with a serious disease other than asthma, assisted by a chest X-ray and other investigations such as bronchoscopy where appropriate. However, the fundamental question for the treating physician is whether or not the young child with wheeze or cough is basically normal or whether the child has the type of increased bronchial responsiveness (bronchial hyperreactivity, BHR) typical of asthma in older subjects. This BHR is documented by performing a bronchial challenge in which an attempt is made to induce a short, controlled attack of bronchospasm (see Figure 1) by a stimulus which would not cause an attack in a healthy individual. The 2008 British guideline on the management of asthma suggests that the role of tests of airway responsiveness (airway hyperreactivity) in the diagnosis of childhood asthma is unclear, but it notes that a negative methacholine test in children has a high negative predictive value and makes a diagnosis of asthma improbable. However, the guideline does not report on the substantial advances which have been made in the use of bronchial challenges in young children - hence this review. The commonest types of stimulus which have been used in children are physical exercise, the inhalation of methacholine, and the inhalation of adenosine $5^{\prime}$ monophosphate (AMP).

Some agents such as methacholine or histamine act
Figure 2. Bronchial challenges by inhalation using methacholine (MCH) and adenosine 5'-monophosphate (AMP) and by physical exercise (E) in 51 children with asthma (A), 21 children with other types of paediatric COPD (C) and in 19 normal children (N). The figure was drawn using the original data available to the author and summarised in the study of Avital et al." The bar graph shows the mean and SD of each parameter. The MCH and AMP data were log transformed and plotted on the log scale on the left vertical axis while the exercise data are plotted on the linear scale on the right vertical axis. The MCH dose was lower (more sensitive) in both $\mathrm{A}$ and $\mathrm{C}$ compared with $\mathbf{N}$. The AMP dose was lower and the fall in lung function greater after exercise (more sensitive) in asthma (A) but the sensitivity of the COPD group (C) was similar to the normal group (N).

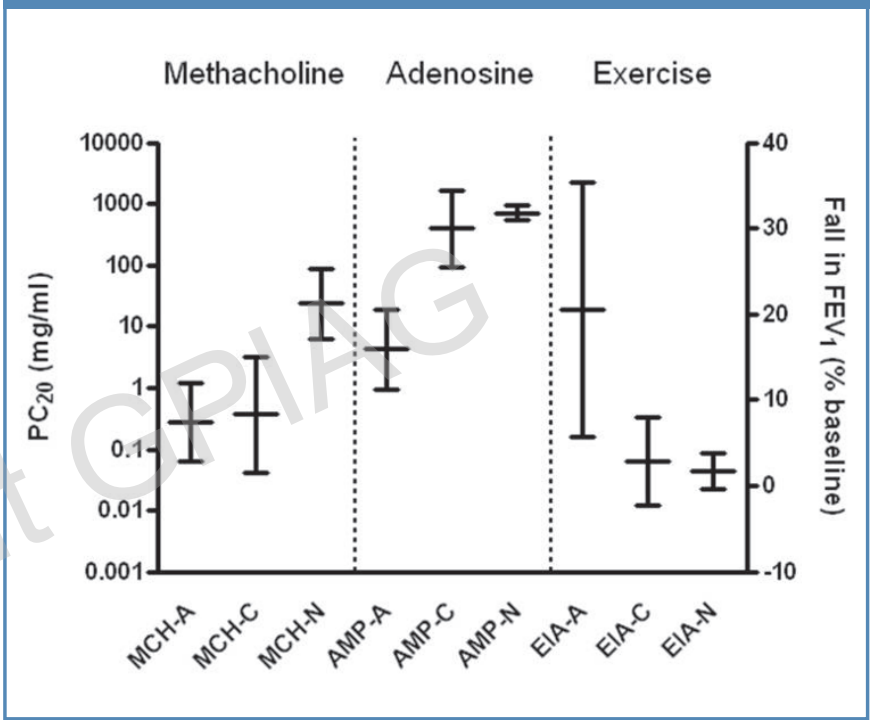

directly on the bronchial smooth muscle to produce bronchospasm, but other stimuli - such as exercise and AMP - appear to act through intermediary pathways ${ }^{8-10}$ and thereby mimic a clinical attack of asthma much more closely. Avital et al. ${ }^{11}$ compared the response of older children with asthma and other types of chronic lung disease to challenges with exercise, methacholine and AMP. As shown in Figure 2, drawn from their original data, they found that methacholine distinguished both asthma and paediatric chronic obstructive lung disease (COPD) from controls with a sensitivity of 82$92 \%$, but did not distinguish between asthma and paediatric COPD. AMP and exercise on the other hand both distinguished asthma from controls with a sensitivity and specificity of $84-98 \%$ but also distinguished asthma from paediatric COPD with a sensitivity and specificity of $85-90 \%$. Using exercise as a challenge is appealing, since most children with asthma have problems with exercise unless they are well controlled by medication. Unfortunately, the response to exercise is very variable (Figure 2 ) and even in the same child the response varies because it depends on the intensity of the 
exercise, the temperature and humidity of the surroundings, and exposure to relevant allergens. ${ }^{12}$

\section{Introducing the 'PCwheeze'}

Based on these observations, an inhalation challenge using AMP should be the best method of distinguishing asthmatic children from both normal children and children with other types of pediatric COPD. Since many children posing diagnostic problems are too young to perform lung function tests, Avital et al. ${ }^{13}$ decided to try to perform bronchial challenges by simply listening for wheeze with a stethoscope. Initially they tried this method on 15 older children who could also perform spirometry; they found that in 11 children wheeze appeared at the same dose (termed the PCwheeze) at which the forced expiratory volume in one second ( $\left.\mathrm{FEV}_{1}\right)$ had fallen by $20 \%\left(\mathrm{PC}_{20}\right)$. To investigate comparative bronchial reactivity in asthmatic children over a wide age range, the same group subsequently used the auscultation technique in 34 preschool asthmatic children and used standard bronchial challenges with spirometry in older asthmatic children. ${ }^{14}$ They found that bronchial reactivity - as measured by the dose of challenge agent provoking the response - was inversely related to the severity of asthma and was independent of age. Further studies of the relationship between the $P C$ wheeze and the $P_{2} C_{20}$ in older subjects ${ }^{15}$ have shown that there is an excellent correlation between the two, but that the PCwheeze is, in fact, approximately $52 \%$ greater than the $P C_{20}$. Koh et al. ${ }^{16}$ studying children with classical asthma as compared with cough variant asthma also noted that the FEV 1 at which wheezing occurred had fallen by an average of $31.4 \%$ and the $P C_{\text {wheeze to }} \mathrm{PC}_{20}$ ratio in typical asthma was about 1.5 to 2.0 .

\section{Efficacy and safety of the PCwheeze challenge}

While some investigators found that only a minority of children wheezed during a challenge, ${ }^{17}$ the majority found wheezing in some $80-90 \%$ at the end point of a challenge. ${ }^{18,19}$ Some of these differences can be explained by the amount of agent delivered. Another factor affecting the incidence of wheezing could be the lack of any clearly defined end point in terms of what was meant by significant wheezing. Bronchial challenges by auscultation have now been undertaken in large numbers of children. None has reported any serious adverse effects. In more recent studies we have always used the additional safeguards of pulse oximetry and respiratory rate, and have halted the challenge - even without the appearance of wheeze - if oxygen saturation fell from baseline by more than $5 \%$ or respiratory rate rose by more than $50 \%$. In the study of 146 young children with asthma (mean age, $4.3 \mathrm{yr}$ ) by Springer et al. ${ }^{19}$ the challenge was terminated in $80.8 \%$ because of wheeze, in $8.6 \%$ by a combination of desaturation and tachypnoea, in $5.7 \%$ by desaturation alone, and in $1.4 \%$ by tachypnoea alone. In older children the severity of hypoxia at the end point of a challenge determined by a $20 \%$ fall in $\mathrm{FEV}_{1}$ is very similar to that in younger children using the PCwheeze method.

Just as a bronchial challenge with AMP is very specific in distinguishing between asthma and COPD using lung function testing to measure the $P C_{20}$, so it is using the PCwheeze in younger children. ${ }^{20}$ Choi et al. ${ }^{21}$ used the auscultation method to explore the relationship between bronchial reactivity and eosinophila as an index of airway inflammation in young asthmatic children. They came to the conclusion that bronchial responsiveness to AMP was more closely related to airway inflammation in young asthmatics than that to methacholine.

\section{Automating the PCwheeze}

A PCwheeze challenge performed in the conventional way by auscultating the chest after each dose of AMP means that the test can only be conducted by an experienced physician and can take up to 45 minutes. The endpoint also depends on the judgment of the physician and is therefore susceptible to human error. With the increased understanding of the nature of wheezing ${ }^{22,23}$ and the ability to record and analyse breath sounds using advanced computer techniques, ${ }^{24,25}$ studies have now been undertaken to define the endpoint of a PCwheeze challenge in acoustic terms. In order to determine the reliability of the opinion of an experienced pediatrician in determining the end point, Godfrey et al. undertook PCwheeze challenges in 51 preschool children using an electronic stethoscope for the auscultation of each lung and for the simultaneous recording of the acoustic sonogram for analysis. ${ }^{26}$ In positive challenges the mean wheeze rate (duration of wheeze/duration of recording, Tw/Ttot) was 28.1\% (95\% Cl: 19.5-36.8\%) while no wheeze was detected acoustically in negative challenges. Using a cut-off Tw/Ttot of $\geq 10 \%$ as truth, clinical wheezing, as detected by the pediatrician, had a sensitivity of $100 \%$ (no false negatives) and a specificity of $91 \%$. It was concluded that the clinical observation of wheeze agrees very well with its detection by acoustic measurement at the end point of a bronchial challenge in preschool children. It was also apparent from this study that in eight of the 22 children, wheeze was only heard over one lung at the endpoint while in one child the wheeze was only inspiratory.

In a further study, Godfrey et al. recorded breath sounds continuously during tidal breathing inhalation challenges with AMP using acoustic sensors attached over each upper lobe in 80 preschool children. ${ }^{27}$ For the challenge to be positive the 
Figure 3. Record showing the frequency and intensity of sound components with time (in seconds, below) recorded from a sensor on the chest wall in a young child during a bronchial challenge. The more intense black, mainly horizontal lines are wheezes which were detected during both inspiration and expiration in the frequency range of about 200-1500 Hz (scale on right). Some of the wheezes had harmonics but the polyphonic nature of most of the record shows wheezing originating from multiple sites.

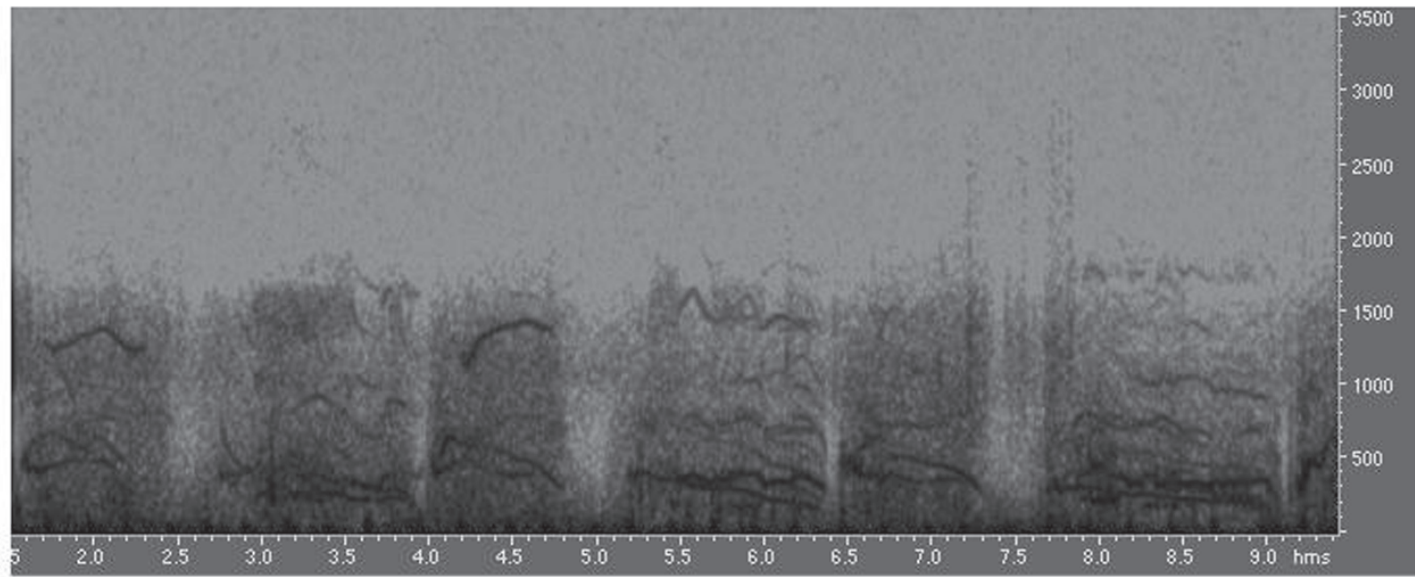

paediatrician had to hear wheeze during five breaths (not necessarily consecutive) during a 45 second period of auscultation. Using acoustic analysis they determined that the first wheeze appeared during the two minute period of nebulisation in $31 \%$ of positive challenges, it was unilateral in $37 \%$, and only inspiratory in $46 \%$. In a further analysis it was found that the large majority of positive challenges were characterised by at least two consecutive breaths with a Tw/Ttot of at least 10\% (Figure 3) with no particular preference with respect to the site of wheeze, breath phase, or tonal characteristic. This end point had a sensitivity of $97.6 \%$ and specificity of $99.7 \%$

\section{The future}

A commercially available device which records and analyses breath sounds and measures the Tw/Ttot in almost real time is now available (Pulmotrack ${ }^{\mathrm{TM}}$, Karmelsonix, Haifa, Israel). An acoustic sensor is attached over the trachea or on the manubrium sterni and another over the lung, while respiratory movements are recorded with a belt around the chest. A calibrated algorithm detects wheeze, rejects ambient noise, and quantifies the wheeze in terms of the wheeze rate (Tw/Tot). In a study of 31 wheezy children aged between 4 months and 5 years attending an emergency clinic, Levy et al. compared the severity of wheezing - as estimated by the child's parents, a clinic nurse and a paediatrician - with the wheeze rate measured acoustically. ${ }^{28}$ They found an excellent correlation between the clinical score of the pediatrician and the wheeze rate, a lower correlation for the estimate by the nurse, and almost no correlation between the parents'
Figure 4. Record from a Pulmotrack ${ }^{\mathrm{TM}}$ during a bronchial challenge with methacholine in an adult. The upper panel shows the wheeze rate (Tw/Ttot) during inspiration, I and expiration E, and the lower panel shows the respiratory rate and inspiratory to expiratory (I/E) ratio. After increasing doses of methacholine the subject began to wheeze and this continued for 3 more measurements until a bronchodilator was administered and the wheeze fell to low levels.

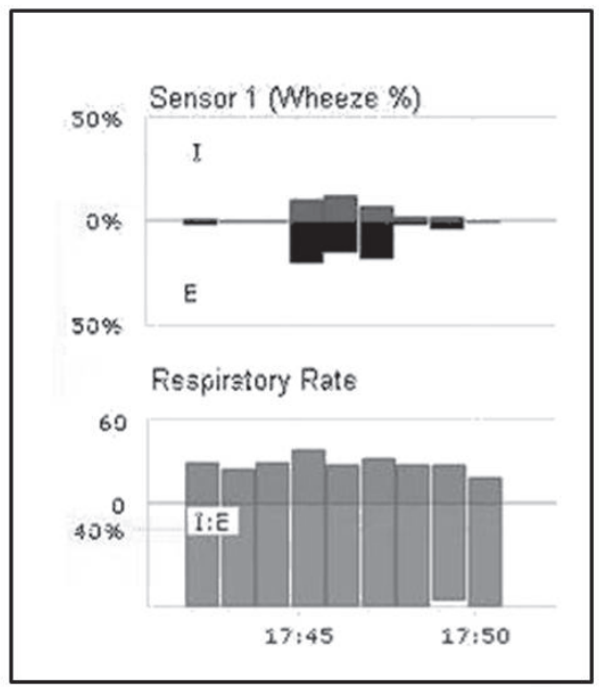

estimate and the wheeze rate.

The use of a Pulmotrack to record data during a bronchial challenge with methacholine in an adult is shown in Figure 4. As increasing doses of methacholine were administered the 
Tw/Ttot increased, and after reaching the endpoint and after a bronchodilator had been given, the wheeze disappeared. The use of a device such as this could greatly simplify PCwheeze challenges which could then be performed by a trained technician.

\section{Conflict of interest declaration}

Professor Godfrey is Chairman of the Medical Scientific Committee of Karmelsonix who manufacture the Pulmotrack. He receives a consultation fee for his services and holds stock options in the company.

\section{References}

1. Bush A. Diagnosis of asthma in children under five. Prim Care Resp J 2007; 16(1):7-15. doi:10.3132.pcri.2007.00001

2. Castile R, Filbrun D, Flucke R, Franklin W, McCoy K. Adult-type pulmonary function tests in infants without respiratory disease. Pediatr Pulmonol 2000; 30:215-27. doi:10.1002/1099-0496(200009)30:3<215::AID-PPUL6>3.0.CO;2-V

3. Godfrey S, Bar-Yishay E, Avital A, Springer C. What is the role of tests of lung function in the management of infants with lung disease? Pediatr Pulmonol 2003;36:1-9. doi:10.1002/ppul.10282

4. Vilozni D, Barak A, Efrati O, Augarten A, Springer C, Yahav Y, Bentur L. The Role of Computer Games in Measuring Spirometry in Healthy and "Asthmatic" Preschool Children. Chest 2005;128:1146-55. doi:10.1378/chest.128.3.1146

5. Hall GL, Hantos Z, Wildhaber JH, Petak F, Sly PD. Methacholine responsiveness in infants assessed with low frequency forced oscillation and forced expiration techniques. Thorax 2001;56:42-47. doi:10.1136/thorax.56.1.42

6. Black J, Baxter-Jones AD, Gordon J, Findlay AL, Helms PJ. Assessment of airway function in young children with asthma: Comparison of spirometry, interrupter technique, and tidal flow by inductance plethsmography. Pediatr Pulmonol 2004;37:548-53. doi:10.1002/ppul.20046

7. British Thoracic Society Scottish Intercollegiate Guidelines Network. British Guideline on the Management of Asthma. Thorax 2008;63(Suppl 4):iv1-121. doi:10.1136/thx.2008.097741

8. Venge P, Henriksen J, Dahl R, Hakansson L. Exercise-induced asthma and the generation of neutrophil chemotactic activity. J Allergy Clin Immunol 1990; 85:498-504. doi:10.1016/0091-6749(90)90161-V

9. Cushley MJ, Holgate ST. Adenosine-induced bronchoconstriction in asthma: role of mast cell-mediator release. J Allergy Clin Immunol 1985;75:272-8. doi:10.1016/0091-6749(85)90057-0

10. Driver AG, Kukoly CA, Metzger WJ, Mustafa SJ. Bronchial challenge with adenosine causes the release of serum neutrophil chemotactic factor in asthma. Am Rev Respir Dis 1991;143:1002-07.

11. Avital A, Springer C, Bar-Yishay E, Godfrey S. Adenosine, methacholine, and exercise challenges in children with asthma or paediatric chronic obstructive pulmonary disease. Thorax 1995;50:511-16. doi:10.1136/thx.50.5.511

12. Godfrey S, Bar-Yishay E. Exercised-induced asthma revisited. Respir Med 1993 87:331-44. doi:10.1016/0954-6111(93)90046-3
13. Avital A, Bar-Yishay E, Springer C, Godfrey S. Bronchial provocation tests in young children using tracheal auscultation. I Pediatr 1988;112:591-4. doi:10.1016/S0022-3476(88)80177-X

14. Avital A, Noviski N, Bar-Yishay E, Springer C, Levy M, Godfrey S. Nonspecific bronchial reactivity in asthmatic children depends on severity but not on age. Am Rev Respir Dis 1991;144:36-8.

15. Noviski N, Cohen L, Springer C, Bar-Yishay E, Avital A, Godfrey S. Bronchial provocation determined by breath sounds compared with lung function. Arch Dis Child 1991;66:952-5. doi:10.1136/adc.66.8.952

16. Koh YY, Chae SA, Main KU. Cough variant asthma is associated with a higher wheezing threshold than classic asthma. Clin Exper Allergy 1993;23:696-701. doi:10.1111/j.1365-2222.1993.tb01796.x

17. Wilson NM, Bridge P, Phagoo SB, Silverman M. The measurement of methacholine responsiveness in 5 year old children: three methods compared. Eur Respir J 1995;8:364-70. doi:10.1183/09031936.95.08030364

18. Yong SC, Smith CM, Wach R, Kurian M, Primhak RA. Methacholine challenge in preschool children: methacholine-induced wheeze versus transcutaneous oximetry. Eur Respir J 1999;14:1175-8. doi:10.1183/09031936.99.14511759

19. Springer C, Godfrey S, Picard E, et al. Efficacy and safety of methacholine bronchial challenge performed by auscultation in young asthmatic children. Am J Respir Crit Care Med 2000; 163:857-60.

20. Avital A, Picard E, Uwyyed K, Springer C. Comparison of adenosine 5'monophosphate and methacholine for the differentiation of asthma from chronic airway diseases with the use of the auscultative method in very young children. J Pediatr 1995;127:438-40. doi:10.1016/S0022-3476(95)70079-X

21. Choi SH, Kim DK, Yu J, Yoo Y, Koh YY. Bronchial responsiveness to methacholine and adenosine 5'-monophosphate in young children with asthma: their relationship with blood eosinophils and serum eosinophil cationic protein. Allergy 2007;62:1119-24. doi:10.1111/j.1398-9995.2007.01412.x

22. Gavriely N, Palti Y, Alroy G, Grotberg JB. Measurement and theory of wheezing breath sounds. J Appl Physiol 1988;57:481-92.

23. Gavriely N, Grotberg JB. Flow limitation and wheezes in a constant flow and volume lung preparation. J App/ Physiol 1988;64:17-20.

24. Fenton TR, Pasterkamp H, Tal A, Chernick V. Automated spectral characterization of wheezing in asthmatic children. IEEE Trans Biomed Eng 1985;32:50-5. doi:10.1109/TBME.1985.325616

25. Sanchez I, Avital A, Wong I, Tal A, Pasterkamp H. Acoustic vs. spirometric assessment of bronchial responsiveness to methacholine in children. Pediatr Pulmonol 1993;15:28-35. doi:10.1002/ppul.1950150105

26. Godfrey S, Uwyyed K, Springer C, Avital A. Is clinical wheezing reliable as the end-point for bronchial challenges in pre-school children. Pediatr Pulmonol 2004;37:193-200. doi:10.1002/ppul.10434

27. Godfrey S, Cohen S, Avital A, Springer C. Timing and nature of wheezing at the end point of a bronchial challenge in preschool children. Pediatr Pulmonol 2005;39:262-7. doi:10.1002/ppul.20178

28. Levy ML, Godfrey S, Irving CS, et al. Wheeze detection in infants and pre-school children: recordings versus assessment of physician and parent. J Asthma 2004; 41:845-53. doi:10.1081/JAS-200038451 